\title{
Effects of Systemic Lidocaine on Postoperative Recovery Quality and Immune Function in Patients Undergoing Laparoscopic Radical Gastrectomy
}

\author{
Xueli $L v^{1, *}$ \\ Xiaoxiao $\mathrm{Li}^{1}{ }^{1} *$ \\ Kedi Guo ${ }^{1, *}$ \\ Tong $\mathrm{Li}^{1}$ \\ Yuping Yang' \\ Wensi Lu' \\ Shuting Wang' \\ Su Liu ${ }^{1,2}$ \\ 'Jiangsu Province Key Laboratory of \\ Anesthesiology, Xuzhou Medical \\ University, Xuzhou, Jiangsu, People's \\ Republic of China; ${ }^{2}$ Department of \\ Anesthesiology, The Affiliated Hospital of \\ Xuzhou Medical University, Xuzhou \\ Medical University, Xuzhou, Jiangsu, \\ People's Republic of China
}

*These authors contributed equally to this work

\begin{abstract}
Objective: This study aimed to explore the effects of lidocaine on postoperative quality of recovery (QoR) and immune function in patients undergoing laparoscopic radical gastrectomy.

Methods: In total, 135 patients were enrolled and were equally randomized to receive low-dose lidocaine (Group LL: $1.5 \mathrm{mg} / \mathrm{kg}$ bolus followed by an infusion at $1.0 \mathrm{mg} / \mathrm{kg} /$ hour) or high-dose lidocaine (Group HL: $1.5 \mathrm{mg} / \mathrm{kg}$ bolus followed by an infusion at $2.0 \mathrm{mg} / \mathrm{kg} /$ hour) or Controls (Group C: received a volume-matched normal saline at the same rate). The primary outcome was a QoR-40 score on postoperative day (POD) 1. Secondary outcomes were a QoR-40 score on POD 3, levels of inflammatory factors (IL-6, IL-10, TNF- $\alpha$ ) and $\mathrm{CD}^{+} \mathrm{T}$ cells, $\mathrm{CD} 8^{+} \mathrm{T}$ cells proportions, and $\mathrm{CD}^{+} / \mathrm{CD}^{+}$cell ratios and postoperative recovery of bowel function.

Results: There were no statistically significant differences in patient characteristics at baseline. The total QoR-40 scores on POD 1 in Group HL (171.4 \pm 3.89$)$ were higher than those in Group LL $(166.20 \pm 4.05)$ and in Group C $(163.40 \pm 4.38)$ (adjusted $P<0.001)$. Differences in the dimension scores of QoR-40 for pain, physical comfort, and emotional state were significant across the three groups. Lidocaine administration significantly reduced the release of IL- 6 , IL-10, TNF- $\alpha$, and attenuated immune changes induced by trauma. Kaplan-Meier curves showed that the median time to the first exhaust and defecation were shorter in the Group HL than in Groups LL and C (1.55 days vs 2.4 days vs 2.6 days, log rank $P<0.0001$; and 2.86 days vs 3.22 days vs 3.46 days, $\log$ rank $P=0.002$, respectively). Additionally, patients in lidocaine groups required less remifentanil consumption and experienced lower pain intensity, compared with the control group.
\end{abstract}

Conclusion: Systemic lidocaine improved postoperative recovery, alleviated inflammation and immunosuppression, and accelerated the return of bowel function, and is thus, worthy of clinical application.

Clinical Trials Registration: ChiCTR2000028934.

Keywords: lidocaine, QoR-40, postoperative quality of life, radical gastrectomy

\section{Introduction}

Gastric carcinoma is the fifth most commonly diagnosed cancer and the third leading cause of cancer-related death. ${ }^{1}$ Surgical resection is the main strategy for gastric carcinoma, and the combination of surgery, chemotherapy, and chemoradiation may improve the survival rate of gastric cancer patients. ${ }^{2,3}$ However, postoperative pain
Department of Anesthesiology, The Affiliated Hospital of Xuzhou Medical University, Xuzhou Medical University,

Xuzhou, Jiangsu, 221000, People's

Republic of China

Tel $+86 \quad 18118309692$

$\mathrm{Fax}+0516-8346-9496$

Email 150040009@qq.com 
management remains a challenging problem after radical gastrectomy given the significant duration of the surgical procedure and trauma. Opioids are commonly used in postoperative analgesia for their powerful analgesic effects. However, the clinically relevant adverse effects accompanying opioids, including ileus, constipation, postoperative nausea, and vomiting, ${ }^{4}$ impose serious negative effects on postoperative recovery. Furthermore, surgical trauma significantly stimulates the release of inflammatory cytokines and influences immune function, which together significantly increase the incidence of postoperative complications, prolong the length of hospital stay, and even promote the metastatic spread of tumor cells. $^{5-7}$

Lidocaine, an adjuvant analgesic, is widely used in nerve block and intravenous infusion for its analgesic, antiarrhythmic, or anti-inflammatory effects. ${ }^{8}$ de Oliveira et al ${ }^{9}$ reported that systemic lidocaine with a bolus of $1.5 \mathrm{mg} / \mathrm{kg}$ followed by infusion at $2.0 \mathrm{mg} / \mathrm{kg} /$ hour effectively reduced the need for opioids and the intensity of postoperative pain prolonging the time to the first request for morphine. Ho et $\mathrm{al}^{10}$ reported prolonging the duration of lidocaine infusion to 48 hours after surgery, and revealed that lidocaine administration reduced opioid consumption by up to $40 \%$ from 24 to 72 hours postoperatively. Furthermore, intravenous lidocaine has the added advantage of alleviating surgical stress and inflammation and reducing surgery-induced immune alterations. ${ }^{11}$ These opioid-sparing and anti-inflammatory effects, in turn, lead to a reduction of complications and acceleration of early recovery of postoperative bowel function, ${ }^{12,13}$ which may improve the quality of recovery and shorten the length of hospital stay. However, whether lidocaine administration could alleviate inflammation and immunosuppression and accelerate the overall postoperative quality of recovery in patients undergoing laparoscopic radical gastrectomy for gastric cancer is still unknown. Therefore, we hypothesized that perioperative administration of systemic lidocaine significantly improves the quality of postoperative recovery, alleviates surgical stress and inflammation, and protects immune function, and thus improves prognosis.

\section{Methods}

This study was a single-center, prospective, double-blind, randomized controlled trial. The protocol was approved by the Ethics Committee of the Affiliated Hospital of Xuzhou Medical University (XYFY2019-KL105-01) and was registered at the Chinese Clinical Trial Registry (ChiCTR2000028934). This study complied with the
Declaration of Helsinki and adhered to CONSORT guidelines. Written informed consent was obtained from all participants before enrollment. This study was performed from 1 October 2019 to 31 October 2020.

\section{Patients}

A total of 138 consecutive patients undergoing laparoscopic radical gastrectomy for gastric carcinoma, aged between 18 and 75 years, with American Society of Anesthesiologists (ASA) physical status I-III were included. The exclusion criteria were: (i) body mass index $(\mathrm{BMI}) \geq 30 \mathrm{~kg} / \mathrm{m}^{2}$; (ii) history of endoscopic submucosal dissection, radiotherapy, chemotherapy; or history of preoperative treatment with anti-inflammatory drugs, analgesics and hormones; (iii) metastases occurring in other distant organs; (iv) preoperative gastrointestinal obstruction or perforation; (v) allergy to research drugs; (vi) severe hepatic or renal diseases; (vii) severe cardiac disease (severe arrhythmia, preexcitation syndrome, II or III atrioventricular block, double-bundle branch block), severe sinoatrial node dysfunction, congestive heart failure; (viii) psychiatric disorders; or (ix) electrolyte disorders, seizure disorders, acid-base status, hypoxemia, hypoalbuminemia, low body weight $(<45 \mathrm{~kg})$, or patients involved in other local anesthetic interventions. Patients, with long surgery duration $(>6 \mathrm{~h})$, or serious adverse events occurring in the perioperative period or those transferred to the intensive care unit (ICU) after surgery were eliminated. Patients experiencing persistent arrhythmia, severe hemodynamic fluctuations, convulsions, tongue and lip numbness, metallic taste, hearing and visual impairment after lidocaine administration were considered as lidocaine-related adverse effects.

\section{Randomization and Masking}

In total, 138 patients were randomly assigned to the lowdose lidocaine group (Group LL), the high-dose lidocaine group (Group HL), or the control group (Group C) by a computer-generated random sequence in a $1: 1: 1$ ratio. The randomization sequence was kept in sealed, opaque envelopes, which was opened by an anesthesia nurse responsible for the preparation of the research drugs after the patient arrived at the operation room. Patients, surgeons, anesthesiologists, and statisticians were all blinded to the patient allocation. 


\section{Study Intervention}

Patients in Group LL were given a bolus injection of lidocaine $1.5 \mathrm{mg} / \mathrm{kg}$ over 15 minutes before induction, which was followed by a continuous infusion at $1.0 \mathrm{mg} /$ $\mathrm{kg} /$ hour until the end of the operation. In Group HL, lidocaine was administered at a same initial loading dose of $1.5 \mathrm{mg} / \mathrm{kg}$ and then infused at $2.0 \mathrm{mg} / \mathrm{kg} /$ hour. While in Group $\mathrm{C}$, individuals received volume-matched normal saline loading dose and infusion as placebo. The study drugs were prepared in a $20-\mathrm{mL}$ (for the bolus administration) and another 20-mL syringe (for the continuous infusion). The former contained $1 \%$ lidocaine solution or an equal amount of $0.9 \%$ normal saline, and the later contained $1 \%$ or $2 \%$ lidocaine, or $0.9 \%$ normal saline solution.

\section{Anesthetic and Perioperative Management}

All patients fasted for 6-8 hours with no preoperative medication. When arriving at the operation room, all patients underwent standard monitoring protocols including electrocardiogram, pulse oxygen saturation, invasive blood pressure, and end-tidal $\mathrm{CO}_{2}\left(\mathrm{ETCO}_{2}\right)$. Additionally, the bispectral index (BIS), surgical pleth index (SPI, a dimensionless score reflecting nociception-antinociception balance, ranging from 0 to 100 and representing minimum and maximum surgical stress levels, respectively ${ }^{14,15}$ ), and responses to trainof-four stimulation (TOF) were also recorded.

Each individual was subjected to a standardized anesthesia technique. General anesthesia was induced by a combination of midazolam $0.05 \mathrm{mg} / \mathrm{kg}$, sufentanil 0.5 $\mu \mathrm{g} / \mathrm{kg}$, etomidate $0.3 \mathrm{mg} / \mathrm{kg}$, and cisatracurium $0.2 \mathrm{mg} / \mathrm{kg}$. After induction of anesthesia, a suitably sized endotracheal tube was intubated under the guidance of a visual laryngoscope, and the relevant ventilator parameters were standardized as: tidal volume (VT), $6-8 \mathrm{~mL} / \mathrm{kg}$; respiratory rate (RR), 12-15 breaths/min; ratio of aspiration to aspiration (I:E), 1:1.5; fraction of inspired oxygen ( $\mathrm{FiO} 2), 100 \%$; and positive end-expiratory pressure (PEEP, $\left.5 \mathrm{cmH}_{2} \mathrm{O}\right)$. If necessary, the ventilator parameters mentioned above could be adjusted slightly, which aimed to maintain the $\mathrm{ETCO}_{2}$ between 35 and $45 \mathrm{mmHg}$. Anesthesia was maintained at 1 MAC sevoflurane combined with remifentanil $0.2-0.4 \mu \mathrm{g} / \mathrm{kg} /$ minute, and adjustments were made according to the BIS index (fluctuating between 40 and 60), SPI index (fluctuating between 20 and 50), and hemodynamic parameters during surgery. An electronic patientcontrolled analgesia (PCA) pump was used to administer postoperative analgesia (sufentanil $2 \mu \mathrm{g} / \mathrm{kg}$ combined with tropisetron $10 \mathrm{mg}$ ). At the end of the surgery, all medications were discontinued, and patients were transferred to the post-anesthesia care unit (PACU) for further observation. Patients were extubated when their vital signs stabilized (the tidal volume was $6-8 \mathrm{~mL} / \mathrm{kg}$, the respiratory frequency was 12-20 breaths/minute, oxygen saturation was $\geq 95 \%$, and the TOF ratio (T4/T1) was $>0.9$ ).

\section{Collection of Blood Samples}

Blood samples of the radial artery were collected at a series of time points including before induction (T0), 2 hours after ventilation (T1), and at the end of surgery (T2). Additionally, venous blood samples were collected at 24 hours (T3) and 72 hours (T4) after the operation. The blood samples collected at the different time points were stored in a refrigerator at $4{ }^{\circ} \mathrm{C}$ and were centrifuged for 10 minutes at $3000 \mathrm{rpm}$. The obtained serum specimens were stored in a refrigerator at $-80^{\circ} \mathrm{C}$ for subsequent testing.

\section{Primary and Secondary Outcomes}

The primary outcome in the study was a total score of QoR-40 on postoperative day (POD) 1. Secondary outcomes were as follows: QoR-40 score on POD 3; levels of pro-inflammatory and anti-inflammatory factors (IL-6, IL-10, TNF- $\alpha$ ), and levels of $\mathrm{CD} 4^{+} \mathrm{T}$ cells, $\mathrm{CD} 8^{+} \mathrm{T}$ cells proportions, and $\mathrm{CD} 4^{+} / \mathrm{CD}^{+}$cell ratios assessed preoperatively (T0), 2 hours after ventilation (T1), at the end of surgery (T2), and at 24 hours (T3) and 72 hours (T4) after the operation; the time to first defecation, first exhaust, out-of-bed mobilization, and PCA request; pain intensity and total consumption of remifentanil. The VAS score was used to evaluate the pain intensity postoperatively. Hemodynamic parameters were also recorded.

\section{Inflammation and Immune Factors Testing} Plasma concentrations of IL- 6 , IL-10, TNF- $\alpha$ were tested by an enzyme-linked immunospecific assay (ELISA) using commercially available kits (Wuhan Cloud-Clone Co., Ltd., Wuhan, China). For the flow cytometric assays, peripheral venous blood samples were collected in EDTAcontaining tubes. The number of $\mathrm{CD}^{+} \mathrm{T}$ cells and $\mathrm{CD} 8$ $\mathrm{T}$ cells was counted using the anti-human CD4-PECY7 monoclonal antibody and anti-human CD8-APC monoclonal antibody, respectively, and were calculated as proportions by immunofluorescence quantitative analysis. 


\section{Statistical Analysis}

A sample size calculation was based that used in previous studies, ${ }^{16,17}$ referring to the average and range of total QoR-40 scores after anesthesia and surgery. A score difference of 10 or more was considered as a clinically relevant improvement or deterioration in the quality of recovery. On this basis, we assumed that the total QoR40 scores in Group HL or Group LL on POD 1 would be 10 points higher than in the Group $\mathrm{C}$, with a standard deviation of 13 , and $\alpha$-and $\beta$-values of 0.05 and 0.1 , respectively. Thus, the calculated sample size was 37 patients for each group. In addition, to allow for a $20 \%$ dropout rate during follow-up, the final sample size was 45 patients per group.

All statistical analyses were performed using SPSS and GraphPad Prism software. For continuous data, Kolmogorov-Smirnov test and Levene's test were used to assess normality and homogeneity. Normally distributed variables were presented as the mean (standard deviation) and were analyzed by one-way repeated-measures ANOVA. Non-normally distributed data were presented as median (IQR) and were analyzed by the Kruskal-Wallis tests. Categorical variables were presented as frequency (\%) and were analyzed by the Chi-squared test or Fisher's exact test. When a difference was found among the three groups, post hoc multiple comparisons were performed and all $P$-values were corrected by the Bonferroni method. Kaplan-Meier estimates were given for the time to first defecation, exhaust, out-of-bed mobilization, and PCA request, and then were compared using the log rank (Mantel-Cox) test. All tests were two-tailed and a $P$-value $<0.05$ was considered a significant difference.

\section{Results}

Initially, 148 patients who underwent laparoscopic radical gastrectomy for gastric cancer were enrolled in this study. Ten participants were subsequently excluded for not satisfying the inclusion criteria or refusing to participate. Thus, 138 individuals were ultimately randomized into the Group HL, Group LL, or Group C. After randomization, three patients were excluded, two for converting to open gastrectomy and one for cancelling the operation. Finally, 135 patients (45 in each group) completed this study (Figure 1). Eligible patients were enrolled consecutively from 1 October 2019 to 31 October 2020, and there were no significant differences with regards to the patients' baseline characteristics (Table 1).
The total QoR-40 scores on POD 1 and POD 3 were lower than preoperative values across the three groups, especially for POD 1 (all $P<0.0001$ ). The total QoR-40 scores on POD 1 in Group HL $(173.93 \pm 2.84)$ were higher than those in Group LL $(166.20 \pm 4.05)$ and in Group

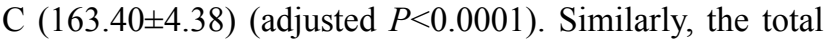
QoR-40 scores on POD 3 in Group HL were also higher than those in other groups $(180.04 \pm 4.00$ vs $173.82 \pm 4.41$ vs $171.42 \pm 3.65$, respectively, adjusted $P<0.001$ ). The differences in the total QoR-40 score between Group HL and Group $\mathrm{C}$ were higher than those between Group LL and Group C on POD 1 (10.53 vs 2.80, $P<0.0001)$ and on POD 3 (8.62 vs $2.40, P<0.0001$ ) (Table 2 ). Similarly, there were significant differences in pain, physical comfort, and emotional state dimensions (all $P<0.0001$ ). However, there were no significant differences in the psychological support and physical independence dimensions on POD 1 or POD 3 among the three groups (all $P>0.05$ ).

There was no statistically significant difference among the three groups in terms of basal levels of IL-6, IL-10, or TNF- $\alpha$ and all levels increased after induction in all groups (all $P<0.0001$ ). The levels of plasma IL-6, IL-10, and TNF- $\alpha$ were greater in Group $C$ than in Group HL from the T1 to T4 time points (all adjusted $P<0.05$ ) (Figure 2) except for the level of TNF- $\alpha$ at T1 $(P=0.172)$ (Figure 2C). Compared with the Group LL, there were no differences regarding levels of TNF- $\alpha$, IL-6, or IL-10 in Group $\mathrm{C}$ across all time points (all adjusted $P>0.05$ ) (Figure 2) except for the levels of IL-10 at T1 and T2 ( $P=0.006$ and $P=0.015$, respectively) (Figure $2 \mathrm{~B}$ ).

There was no obvious difference in the proportion of $\mathrm{CD} 4^{+} \mathrm{T}$ cells, $\mathrm{CD} 8^{+} \mathrm{T}$ cells, or $\mathrm{CD} 4^{+} / \mathrm{CD}^{+}$cell ratios among the three groups at baseline. After induction, the proportions of $\mathrm{CD} 4^{+} \mathrm{T}$ cells and $\mathrm{CD} 4^{+} / \mathrm{CD} 8^{+}$cell ratios significantly decreased, compared with baseline levels (all $P<0.0001$ ), and then gradually increased after the T3 time point. Inversely, the levels of $\mathrm{CD}^{+} \mathrm{T}$ cells significantly increased after induction and reached a peak at the $\mathrm{T} 2$ time point, and then gradually decreased. The proportions of $\mathrm{CD}^{+} \mathrm{T}$ cells and $\mathrm{CD} 4^{+} / \mathrm{CD}^{+}$were greater in Group HL than in Group $\mathrm{C}$ at the T1 to T4 time points (all adjusted $P<0.05$ ) (Figure 2). There were no differences in the proportions of $\mathrm{CD} 4^{+} \mathrm{T}$ cells and $\mathrm{CD} 8^{+} \mathrm{T}$ cells, or in $\mathrm{CD}^{+} / \mathrm{CD}^{+}$cell ratios at all time points between Group LL and Group C (all adjusted $P>0.05$ ) (Figure 2) except for the proportion of $\mathrm{CD}^{+} \mathrm{T}$ cells at $\mathrm{T} 2 \quad(P=0.048)$ (Figure 2D). 


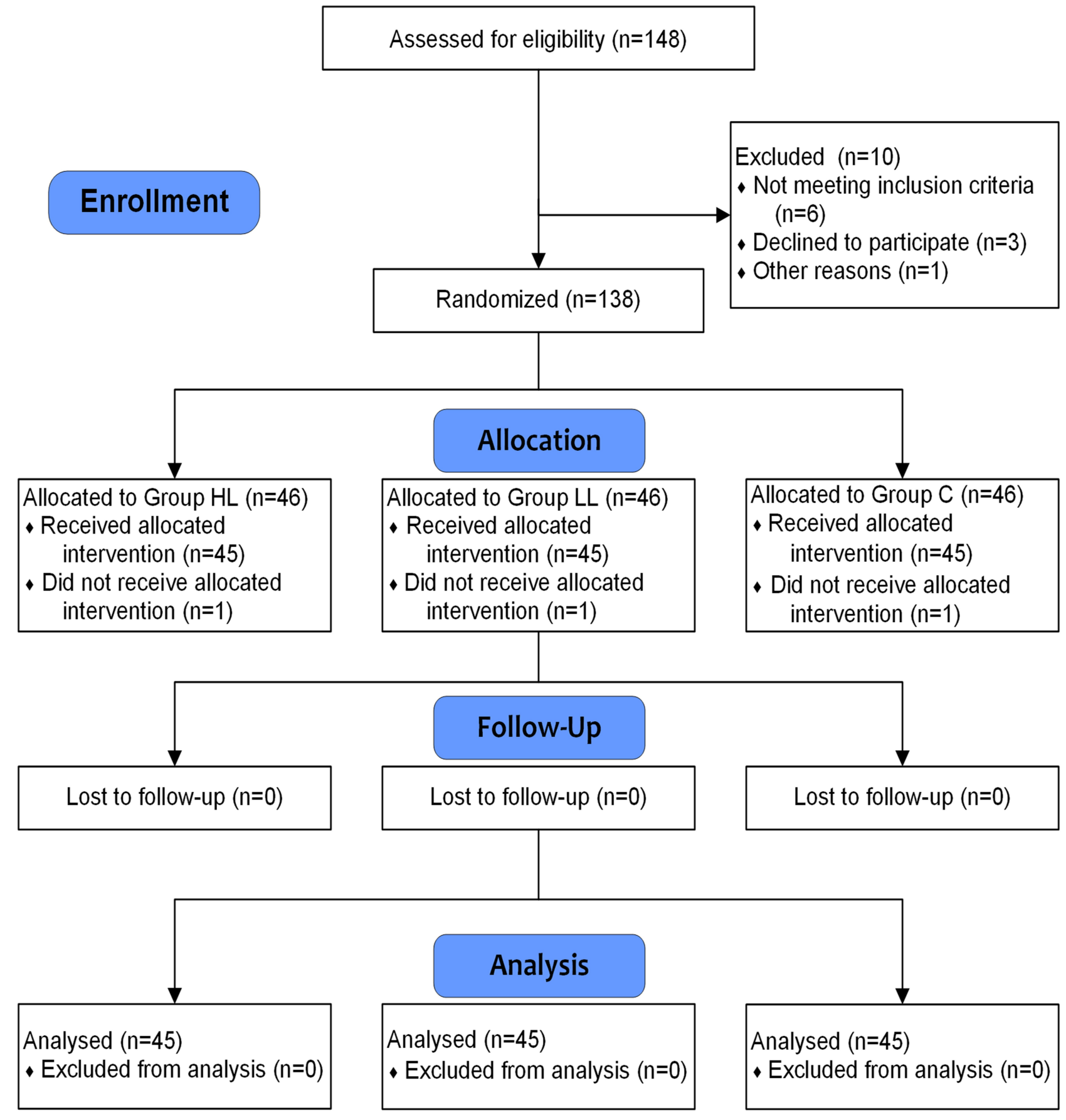

Figure I Study population flow diagram.

The Kaplan-Meier curve analysis revealed that patients in Group HL recovered faster than those in Group LL or Group C. The median time to the first exhaust was shorter in Group HL than in Group LL or Group C (1.55 days vs 2.4 days vs 2.6 days, respectively; $\log$ rank test $P<0.0001)$. Similarly, the median time to the first defecation and PCA request were significantly decreased in Group HL compared with the other two groups (2.86 days vs 3.22 days vs 3.46 days; Log rank test $P=0.0002$; and $52.96 \mathrm{~min}$ vs $39.69 \mathrm{~min}$ vs $34.93 \mathrm{~min}$, log rank $\mathrm{P}<0.0001$, respectively) (Figure 3). However, there was no significant difference in the median time to out-of-bed mobilization (Log rank test $P=0.0538$, Figure 3C).

There was no statistically significant difference among the three groups regarding intraoperative variables or hemodynamic parameters except for reduced remifentanil 
Table I Demographic Profiles at Baseline Among Three Groups

\begin{tabular}{|c|c|c|c|c|}
\hline Variables & $\begin{array}{c}\text { Group HL } \\
\quad(n=45)\end{array}$ & $\begin{array}{c}\text { Group LL } \\
\qquad(n=45)\end{array}$ & $\begin{array}{c}\text { Group C } \\
(n=45)\end{array}$ & $P$-value \\
\hline Age, $y r$ & $53.18 \pm 10.86$ & $54.13 \pm 10.98$ & $54.42 \pm 9.58$ & 0.759 \\
\hline BMI, $\mathrm{kg} / \mathrm{m}^{2}$ & $24.20 \pm 3.06$ & $24.14 \pm 2.75$ & $24.34 \pm 2.97$ & 0.947 \\
\hline \multicolumn{5}{|l|}{ Sex, n (\%) } \\
\hline Male & $29(64)$ & $30(67)$ & $30(67)$ & 0.968 \\
\hline Female & $16(36)$ & $15(33)$ & $15(33)$ & \\
\hline \multicolumn{5}{|l|}{ ASA physical status, n (\%) } \\
\hline 1 & 16 & 17 & 18 & 0.991 \\
\hline II & 24 & 23 & 23 & \\
\hline III & 5 & 5 & 4 & \\
\hline Hypertension, n (\%) & $19(42)$ & $21(47)$ & $20(44)$ & 0.914 \\
\hline Diabetes, n (\%) & $15(33)$ & $15(33)$ & $14(33)$ & 0.967 \\
\hline \multicolumn{5}{|l|}{ Gastrectomy, n (\%) } \\
\hline Distal & $10(22)$ & $12(27)$ & II (24) & 0.887 \\
\hline Total & $35(78)$ & $33(73)$ & $34(76)$ & \\
\hline Length of incision, $\mathrm{cm}$ & $5.90 \pm 0.81$ & $6.11 \pm 0.59$ & $5.85 \pm 0.70$ & 0.191 \\
\hline $\begin{array}{l}\text { Preoperative total QoR-40 } \\
\text { scores }\end{array}$ & $183.40 \pm 3.65$ & $184.16 \pm 2.65$ & $184.40 \pm 4.00$ & 0.366 \\
\hline
\end{tabular}

Notes: Data are presented as mean \pm SD or numbers (\%). Group HL= the high-dose lidocaine group; Group LL= the low-dose lidocaine group; Group $\mathrm{C}=$ the control group. Abbreviations: BMI, body mass index; ASA, American Society of Anesthesiologists; QoR-40, quality of recovery 40.

Table 2 Differences of QoR-40 Scores Between Groups

\begin{tabular}{|c|c|c|c|c|}
\hline Value & $\begin{array}{l}\text { Difference from Group } \\
\text { HL to Group C }\end{array}$ & $\begin{array}{c}\text { Difference from Group } \\
\text { LL to Group C }\end{array}$ & $\begin{array}{c}\text { Difference from Group } \\
\text { HL to Group LL }\end{array}$ & $P$-value \\
\hline \multicolumn{5}{|c|}{ Global QoR-40 } \\
\hline PODI & $10.53(8.55$ to 12.60$) *$ & $2.80(0.70$ to 4.90$) *$ & $7.73(5.75$ to 9.80$) *$ & $<0.001$ \\
\hline POD3 & $8.62(6.56$ to 10.68$) *$ & $2.40(0.34$ to 4.46$) *$ & $6.22(4.16$ to 8.28$) *$ & $<0.001$ \\
\hline \multicolumn{5}{|c|}{ QoR-40 dimensions } \\
\hline \multicolumn{5}{|l|}{ Pain } \\
\hline PODI & $4.1 \mathrm{I}(3.45$ to 4.78$) *$ & I.62(0.99 to 2.25$) *$ & $2.49(1.82$ to 3.15$) *$ & $<0.001$ \\
\hline POD3 & $3.67(2.69$ to 4.64$) *$ & $0.69(-0.29$ to 1.66$)$ & $2.98(2.00$ to 3.95$) *$ & $<0.001$ \\
\hline \multicolumn{5}{|c|}{ Physical comfort } \\
\hline PODI & $2.91(1.89$ to 3.93$) *$ & $1.04(-0.05$ to 2.14$)$ & $\mathrm{I} .87(0.82$ to $2.9 \mathrm{I}) *$ & $<0.001$ \\
\hline POD3 & $1.67(0.72$ to 2.62$) *$ & $1.09(0.14$ to 2.04$) *$ & $0.58(-0.37$ to 1.53$)$ & $<0.001$ \\
\hline \multicolumn{5}{|c|}{ Psychological support } \\
\hline PODI & $0.22(-0.38$ to 0.83$)$ & $-0.24(-0.85$ to 0.36$)$ & $0.47(-0.14$ tol. .07$)$ & 0.177 \\
\hline POD3 & $0.42(-0.33$ to 1.17$)$ & $-0.11(-0.86$ to 0.64$)$ & $0.53(-0.22$ to 1.28$)$ & 0.194 \\
\hline \multicolumn{5}{|c|}{ Physical independence } \\
\hline PODI & $-0.38(-1.01$ to 0.25$)$ & $-0.18(-0.81$ to 0.45$)$ & $-0.20(-0.83$ to 0.43$)$ & 0.350 \\
\hline POD3 & $-0.3 \mid(-0.9 \mid$ to 0.28$)$ & $-0.20 /(-0.79$ to 0.39$)$ & $-0.1 I(-0.7 \mid$ to 0.48$)$ & 0.440 \\
\hline \multicolumn{5}{|c|}{ Emotional state } \\
\hline PODI & $3.44(2.45$ to 4.44$) *$ & $0.56(-0.49$ to 1.60$)$ & $2.89(1.90$ to 3.88$) *$ & $<0.001$ \\
\hline POD3 & $\mathrm{I} .84(0.84$ to 2.85$) *$ & $0.69(-0.32$ to 1.70$)$ & $1.16(0.15$ to 2.16$) *$ & $<0.001$ \\
\hline
\end{tabular}

Notes: Data are presented as mean $(98.3 \% \mathrm{Cl})$. Group $\mathrm{HL}=$ the high-does lidocaine group; Group $\mathrm{LL}=$ the low-dose lidocaine group; Group $\mathrm{C}=$ the control group. *Adjusted $P<0.05$ between groups.

Abbreviation: POD, postoperative day. 

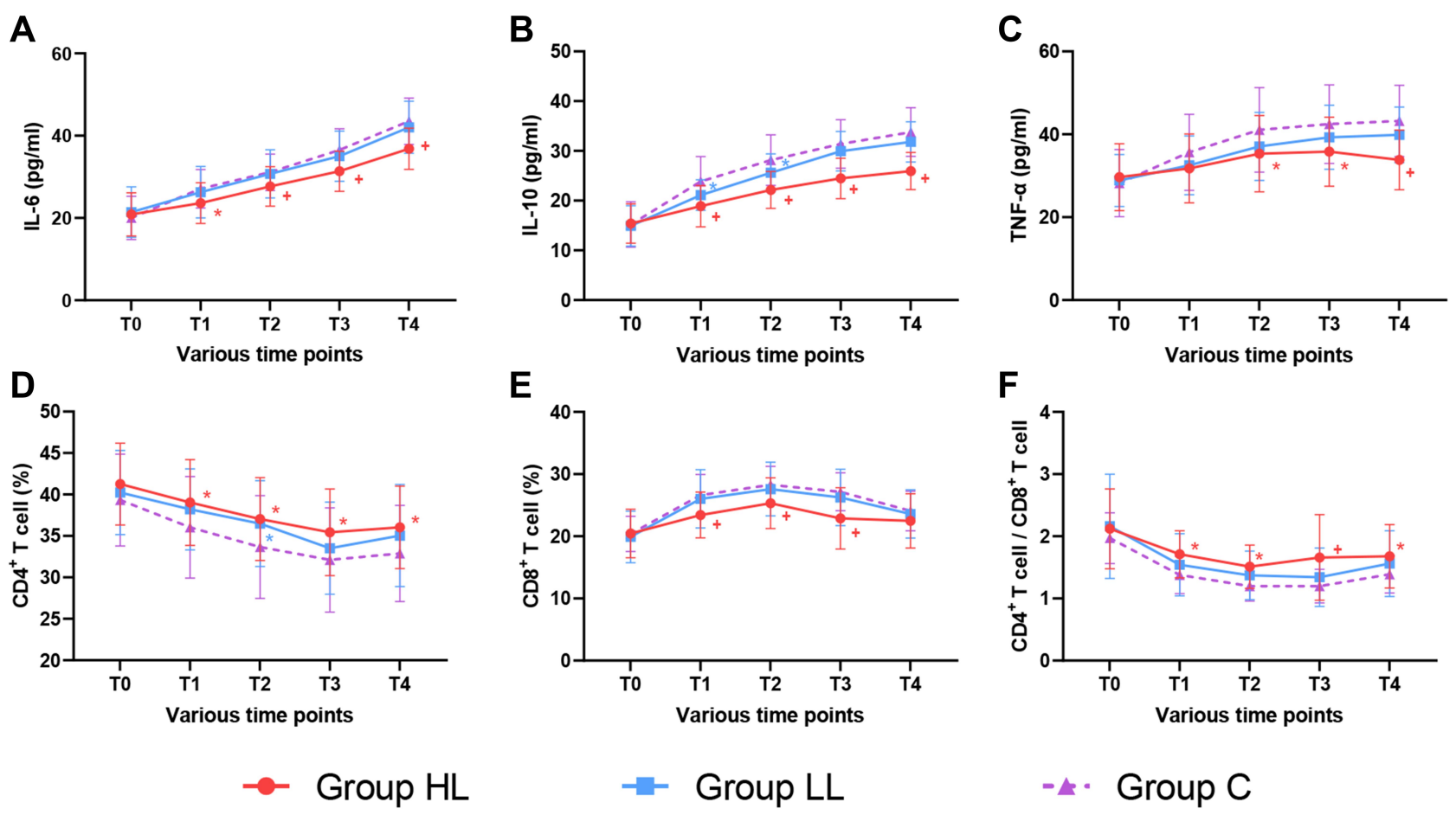

Figure 2 Serial changes in plasma concentrations of IL-6, IL- 10 and TNF- $\alpha, C D 4^{+} \mathrm{T}$ cells, CD8 ${ }^{+} \mathrm{T}$ cells proportions and $\mathrm{CD} 4^{+} / \mathrm{CD} 8^{+}$cell ratios among three groups. Notes: Data are presented as mean \pm SD, Group HL= the high-does lidocaine group; Group LL= the low-dose lidocaine group; Group C= the control group. (A) serum IL-6

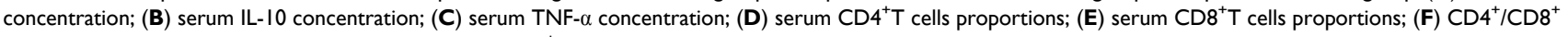
cell ratios. *Adjusted $P<0.05$ different from the group $C$. ${ }^{+}$Adjusted $P<0.05$ different from the other groups.

Abbreviations: T0, baseline; TI, $2 \mathrm{~h}$ after ventilation; T2, the end of surgery; T3, $24 \mathrm{~h}$ after surgery; T4, $72 \mathrm{~h}$ after surgery.

administration in Group HL (3.70 $\pm 0.75 \mathrm{mg})$, compared with Group LL $(4.26 \pm 0.77 \mathrm{mg})$ and Group C (4.67 $\pm 0.92 \mathrm{mg})(P<0.001$; Table 3$)$. Patients in Group HL showed lower pain intensity at rest and movement from 30 minutes to 12 hours postoperatively than in Group $\mathrm{C}$ (all adjusted $P<0.05$ ). There was no significant difference in pain intensity at rest and movement between Group LL and Group C at various time points except for the VAS score at rest at the T1 time point $(3.91 \pm 1.04$ vs $4.31 \pm 0.87 ; P=0.002$ ) (Table 3 ). Additionally, there was no significant difference in postoperative adverse effects experienced across the three groups except that the incidence of postoperative nausea in Group HL was significantly reduced, compared with Groups LL and C (11\% vs $29 \%$ vs $33 \%$; $P=0.034$ ). However, there was no significant difference in the length of hospital stay among the three groups $(P=0.168)$.

\section{Discussion}

In this single-center prospective, double-blind, randomized controlled trial, we found that systemic application of lidocaine could significantly enhance early post-surgical recovery of patients undergoing laparoscopic radical gastrectomy, by decreasing the cytokines levels, protecting immune function, reducing opioid consumption, and improving the recovery of intestinal function.

QoR-40 is the most comprehensive assessment scale to evaluate a patient's overall health status postoperatively, the higher the score, the better the post-surgical recovery. ${ }^{18,19}$ Previous studies have demonstrated that a score difference of 10 or more is a clinically relevant improvement or deterioration in the quality of recovery. ${ }^{16}$ In this study, the total QoR40 scores for the three groups on POD 1 and POD 3 decreased significantly in comparison to the baseline scores, indicating significant negative effects of surgical and anesthesia on post-surgical quality of life. The difference between Group HL and Group C was more than 10 points and between Group LL and Group C was only 2.8 points, demonstrating that a relative high dose of lidocaine infusion exerted positive effect on the patients' postoperative quality of life, which was consistent with previous results. ${ }^{20}$ Furthermore, the scores relative to the pain and physical comfort dimension were significant higher in Group HL than in Group C. In patients receiving perioperative systemic lidocaine infusion, especially in Group HL, less moderate-tosevere pain and low VAS scores, and short median time to 
A

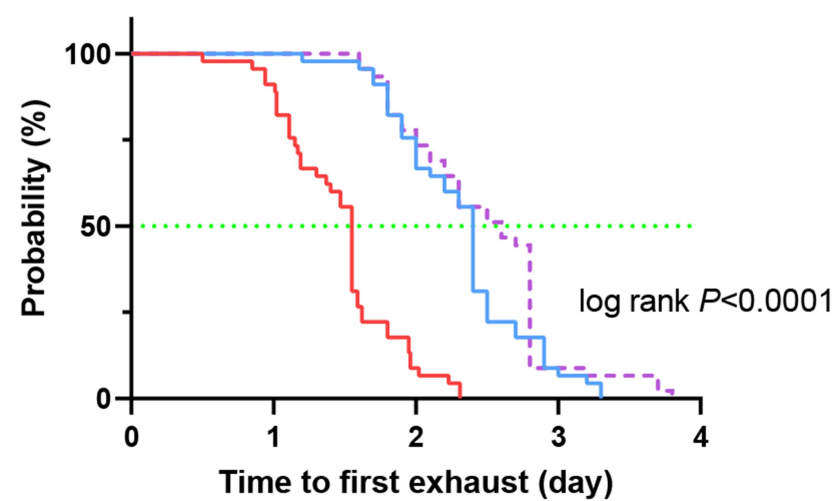

C

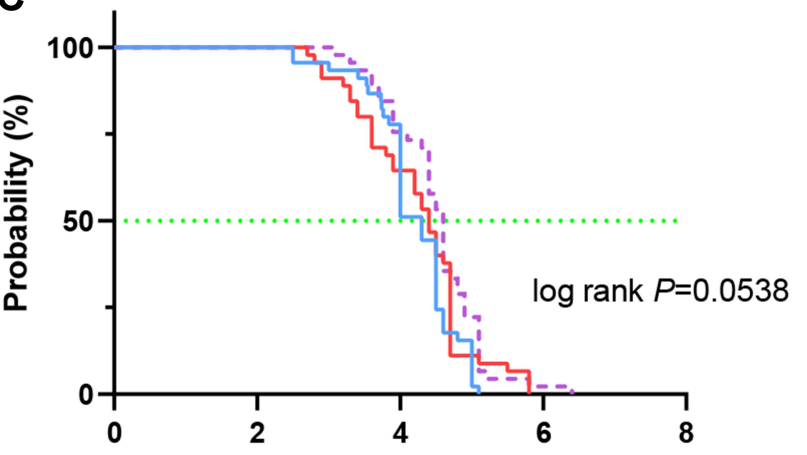

Time to first out-of-bed mobilization (day)
B

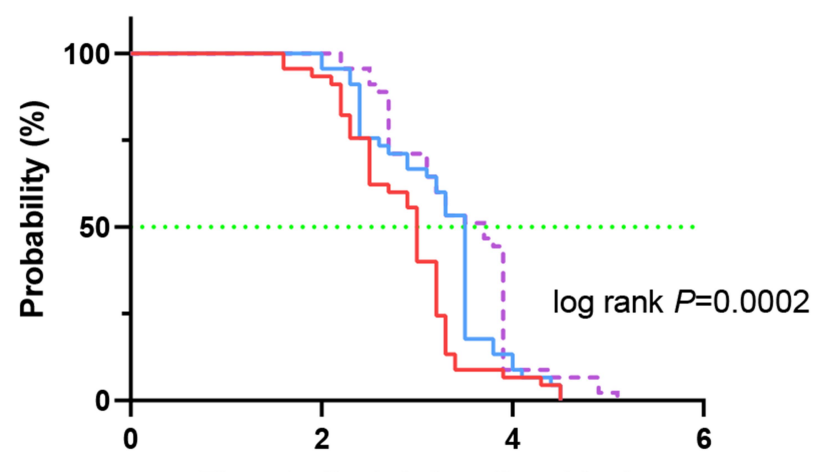

Time to first defecation (day)

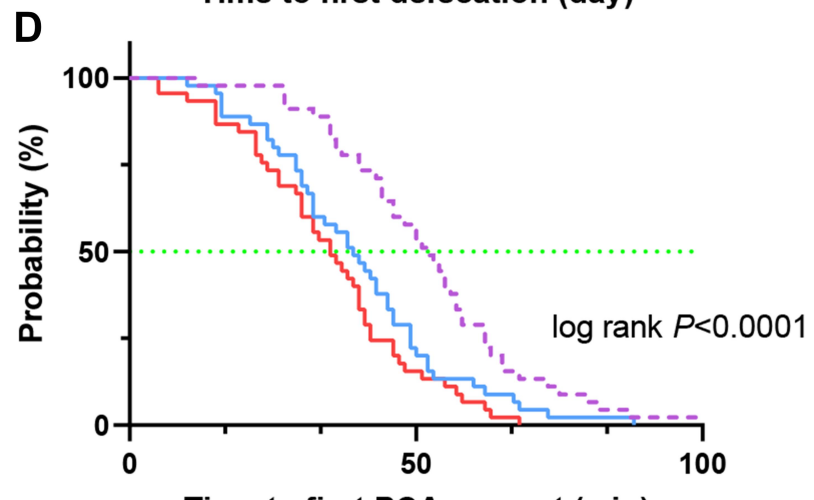

Time to first PCA request ( $\mathrm{min})$

Figure 3 Kaplan-Meier curves for time to first exhaust, defecation, out-of-bed mobilization and PCA request.

Notes: Data are presented as mean \pm SD, Group HL= the high-does lidocaine group; Group LL= the low-dose lidocaine group; Group C= the control group. (A) the time to first exhaust; (B) the time to first defecation; (C) the time to first out-of-bed mobilization; (D) the time to first PCA request.

Abbreviation: PCA, patient-controlled analgesia.

first PCA request were achieved compared to Group C, indicating intravenous lidocaine could reduce pain intensity postoperatively and improve the pain dimension score. In addition, the physical comfort scale of the QoR-40 scale mainly contains items related to post-surgical adverse effects including nausea. ${ }^{21}$ The incidence of postoperative nausea in Group HL significantly decreased by $22 \%$ compared with Group C, which may explain why Group HL patients felt more comfortable It is noteworthy that patients in Group HL showed better emotional state and were less prone to depression, irritability, and sleep disorders than those in Group C. This may be associated with the overall improvement in pain and physical comfort dimensions, indicating that lidocaine administration significantly improved postoperative quality of life both physically and psychologically.

An additional important finding in this study was the inhibitory effect of intravenous lidocaine on the release of cytokines IL-6, IL-10, and TNF- $\alpha$. Surgical trauma significantly stimulates the release of inflammatory cytokines, and
IL-6, IL-10, and TNF- $\alpha$ are commonly measured to access stress responses. ${ }^{22,23}$ Further, these cytokines have also been associated with long-term prognosis of gastric cancer patients. $^{24}$ In this study, consistent with previous results, ${ }^{11,13}$ plasma cytokine concentrations of IL-6, IL-10, TNF- $\alpha$ were significantly increased after induction compared with levels at the preoperative timepoint, providing evidence of an inflammatory response after surgical stimulation. In Group HL, the levels of plasma IL-6, IL-10, and TNF- $\alpha$ were lower than those in Groups LL or C at various time points, which demonstrated that a relatively high-dose of lidocaine could alleviate the inflammatory response induced by surgical procedures, which was consistent with previous studies. ${ }^{12,25,26}$ However, de Oliveira et $\mathrm{al}^{9}$ reached an opposing conclusion, whereby intravenous lidocaine failed to interfere with the production of IL- 6 , an outcome that was similar to another study, ${ }^{27}$ in which blood samples were tested preoperatively, and at 1 hour and 5 hours after the start of surgery, and at 24 hours postoperatively. In this study, 
Table 3 Comparisons of Perioperative Parameters in Three Groups

\begin{tabular}{|c|c|c|c|c|}
\hline Variables & Group HL $(n=45)$ & Group LL $(n=45)$ & Group C (n=45) & $P$-value \\
\hline \multicolumn{5}{|l|}{ Intraoperative outcomes } \\
\hline Surgical duration, min & $260.91 \pm 33.04$ & $263.60 \pm 29.85$ & $265.62 \pm 30.52$ & 0.773 \\
\hline Anesthesia duration, min & $313.93 \pm 32.02$ & $311.24 \pm 33.01$ & $309.40 \pm 33.57$ & 0.806 \\
\hline Propofol dose, mg & $496.44 \pm 77.38$ & $504.89 \pm 75.64$ & $521.78 \pm 65.51$ & 0.249 \\
\hline Remifentanil dose, $\mathrm{mg}$ & $3.70 \pm 0.75^{+}$ & $4.26 \pm 0.77 *$ & $4.67 \pm 0.92$ & $<0.001$ \\
\hline Transfusion volume, $\mathrm{mL}$ & $2728.89 \pm 420.29$ & $2604.44 \pm 374.75$ & $2762.22 \pm 188.64$ & 0.075 \\
\hline Urine output, $\mathrm{mL}$ & $505.56 \pm 93.68$ & $466.67 \pm 66.57$ & $497.22 \pm 82.27$ & 0.062 \\
\hline Estimated blood loss, $\mathrm{mL}$ & $226.67 \pm 89.57$ & $240.00 \pm 92.69$ & $220.00 \pm 83.53$ & 0.554 \\
\hline \multicolumn{5}{|l|}{ SBP, mmHg } \\
\hline T0 & $|38.40 \pm 1| .09$ & $133.27 \pm 17.54$ & $135.69 \pm 12.50$ & 0.223 \\
\hline TI & $121.33 \pm 10.12$ & || $8.7| \pm| \mid .88$ & $|17.07 \pm| 3.3 \mid$ & 0.230 \\
\hline $\mathrm{T} 2$ & $119.69 \pm 11.13$ & $|22.53 \pm| 2.8 \mid$ & $118.78 \pm 13.50$ & 0.335 \\
\hline \multicolumn{5}{|l|}{$\mathrm{HR}$, beats/min } \\
\hline T0 & $82.38 \pm 5.92$ & $81.40 \pm 8.14$ & $79.71 \pm 6.51$ & 0.185 \\
\hline TI & $74.96 \pm 2.99$ & $74.07 \pm 3.78$ & $73.64 \pm 3.31$ & 0.175 \\
\hline $\mathrm{T} 2$ & $73.11 \pm 3.07$ & $74.16 \pm 4.22$ & $74.98 \pm 5.25$ & 0.128 \\
\hline \multicolumn{5}{|l|}{ Postoperative outcomes } \\
\hline \multicolumn{5}{|l|}{ Pain score at rest } \\
\hline $30 \min$ & $3.56 \pm 1.00 *$ & $3.91 \pm 1.04 *$ & $4.31 \pm 0.87^{+}$ & 0.002 \\
\hline $6 \mathrm{~h}$ & $4.02 \pm 0.81^{+}$ & $4.98 \pm 1.01$ & $5.02 \pm 0.92$ & $<0.001$ \\
\hline $12 \mathrm{~h}$ & $3.78 \pm 0.77^{+}$ & $4.60 \pm 0.96$ & $4.78 \pm 0.97$ & $<0.001$ \\
\hline $24 \mathrm{~h}$ & $2.62 \pm 0.81$ & $3.02 \pm 1.08$ & $3.07 \pm 1.21$ & 0.089 \\
\hline \multicolumn{5}{|l|}{ Pain score on movement } \\
\hline $30 \mathrm{~min}$ & $4.38 \pm 1.23^{*}$ & $4.87 \pm 0.84$ & $5.31 \pm 1.10$ & $<0.001$ \\
\hline $6 \mathrm{~h}$ & $5.16 \pm 0.85^{+}$ & $6.29 \pm|.4|$ & $6.47 \pm 1.23$ & $<0.001$ \\
\hline $12 \mathrm{~h}$ & $5.02 \pm 0.99^{+}$ & $5.58 \pm 1.06$ & $5.69 \pm 1.00$ & 0.005 \\
\hline $24 \mathrm{~h}$ & $3.73 \pm 1.27$ & $3.98 \pm 1.47$ & $4.04 \pm 1.19$ & 0.498 \\
\hline Nausea, n (\%) & $5(I I)$ & 13(29) & I5(33) & 0.034 \\
\hline Vomiting, n (\%) & $3(7)$ & $5(I I)$ & $7(16)$ & 0.407 \\
\hline Shivering, n (\%) & $6(13)$ & $8(18)$ & $9(20)$ & 0.693 \\
\hline Length of hospital stay, d & $13.02 \pm 2.19$ & $12.89 \pm 2.11$ & $13.69 \pm 2.11$ & 0.168 \\
\hline
\end{tabular}

Notes: Data are presented as mean \pm SD or numbers (\%). Group HL= the high-does lidocaine group; Group LL= the low-dose lidocaine group; Group C= the control group. *Adjusted $P<0.05$ different from the group $C$. ${ }^{+}$Adjusted $P<0.05$ different from the other groups.

Abbreviations: HR, heart rate; SBP, systolic blood pressure; T0, before induction; TI, $2 \mathrm{~h}$ after ventilation; T2, the end of surgery.

differently from Oliveira et al, IL-6 measurements were taken prior to the start of surgery, 2 hours after ventilation, at the end of surgery, and at POD 1 and POD 3. Our observations are in line with those described by Lin et al, ${ }^{28}$ whereby IL-6 was detectable within $60 \mathrm{~min}$, reached a peak concentration between 4 and 6 hours, and then remained detectable for 10 days after tissue damage. Therefore, the differences in conclusions may be due to different types of surgery and monitoring time points.

In this study, the proportion of $\mathrm{CD}^{+} \mathrm{T}$ cells and $\mathrm{CD}^{+} /$ $\mathrm{CD} 8^{+}$ratios decreased significantly after induction, and the proportion of $\mathrm{CD}^{+} \mathrm{T}$ cells significantly increased, especially at the $\mathrm{T} 1$ timepoint ( 2 hours after ventilation), and then gradually decreased postoperatively, which provided evidence supporting the perioperative inhibition of immune function. $\mathrm{CD}^{+} \mathrm{T}$ cells and $\mathrm{CD} 8^{+} \mathrm{T}$ cells are helper and cytotoxic $\mathrm{T}$ cells, respectively, and exert antitumor effects. ${ }^{29,30}$ The $\mathrm{CD}^{+} / \mathrm{CD} 8^{+}$ratio reflects the body's immune state balance. The lower the ratio, the worse the body's immune function, and a low ratio was considered an index of poor prognosis, which may lead to the formation of tumor metastases. ${ }^{31-33}$ Of note, patients in Group HL showed higher $\mathrm{CD} 4^{+} / \mathrm{CD}^{+} \mathrm{T}$ cell ratios at all time points than those in other two groups, suggesting that a relatively high dose of lidocaine could alleviate immunosuppression and may preserve immune function. 
The efficacy of lidocaine on the recovery of postoperative intestinal function has not been studied conclusively. Some authors ${ }^{34,35}$ have reported that lidocaine failed to improve postoperative intestinal function, while others ${ }^{12,13}$ have come to the opposite conclusion. In our study, patients in Group HL showed decreased median time to first defecation and exhaust postoperatively, demonstrating intravenous lidocaine could shorten the duration of postoperative ileus and accelerate postoperative recovery of bowel function. However, the exact mechanism underlying the accelerated effect on recovery of bowel function of lidocaine remains elusive. Previous animal and clinical studies have revealed that lidocaine contracts circular and longitudinal smooth muscles, ${ }^{36}$ reduces the permeability of lipopolysaccharide jejunum after ischemia, and accelerates the recovery of mucosal barrier, ${ }^{37}$ inhibits inflammatory responses, and protects epithelial intestinal cells. ${ }^{38}$ Furthermore, excessive use of opioids inhibits gastrointestinal motility and increases intestinal mucosal permeability, ${ }^{39}$ which may aggravate postoperative ileus. In our study, patients in the lidocaine-treated group exhibited decreased inflammatory responses and reduced remifentanil consumption than those in the control group, which all together may explain why intravenous lidocaine could accelerate postoperative recovery of intestinal function.

Intravenous lidocaine may also cause various adverse effects, including tongue and lip numbness, metallic taste in the mouth, dizziness, convulsions, and arrhythmias. In this study, all patients received dynamic monitoring of vital signs after arriving at the operation room. Although few patients developed bradycardia during the procedure, all events were transient and without significant PR prolongation or QRS widening on the ECG; therefore, we did not classify these as lidocaine-related toxicity. None of the patients experienced persistent arrhythmias, convulsions, or other serious adverse effects during the surgical procedure. During the postoperative follow-up period, no side effects related to lidocaine were observed. Therefore, there were no patients lost to follow-up. Furthermore, the lidocaine regimen we had chosen was based on previous studies, ${ }^{8,9}$ and we discontinued infusion at the end of the surgery; thus, the total lidocaine administration in our study was relatively small. In addition, Carabalona et $\mathrm{al}^{40}$ monitored serum concentrations of lidocaine following a $1.5 \mathrm{mg} / \mathrm{kg}$ bolus and continued infusion at $2.0 \mathrm{mg} / \mathrm{kg} /$ hour. They found that the median serum concentration of lidocaine was $1.45(0.98-1.88) \mu \mathrm{g} / \mathrm{mL}$, serum concentrations of lidocaine did not increase above $5 \mu \mathrm{g} / \mathrm{mL}$, and no lidocaine related adverse effects were observed. Therefore, the lidocaine dose in our study was within a safe range.

The conclusions of this study were obtained in the context of certain limitations. Firstly, we did not directly measure the plasma concentrations of lidocaine. The lidocaine dose in our study was based on those used in previous studies ${ }^{8,9}$ and on results of relevant meta-analysis. ${ }^{41}$ However, all patients were continuously monitored for 24 hours after surgery and none showed evidence of lidocaine-related toxicity. Secondly, previous studies explored different infusion durations and rates of lidocaine administration, mainly ranging from the end of the surgery to 48 hours after operation and from $1.0 \mathrm{mg} / \mathrm{kg} /$ hour to $3.0 \mathrm{mg} / \mathrm{kg} /$ hour, respectively. ${ }^{10,41} \mathrm{In}$ our study, only two doses of lidocaine were used and infusion lasted up to the end of surgery. Therefore, the optimal dose of lidocaine on acceleration of postoperative quality of recovery remains to be further evaluated. Thirdly, patients were followed up for only 3 days after the procedure and further studies are needed to evaluate the effects of intravenous lidocaine on long-term recovery. Fourthly, several recent studies have reported the anti-tumoral effect of lidocaine; ${ }^{42,43}$ our study only focused on the antiinflammatory and immune protective effects of lidocaine on patients undergoing radical gastrectomy for gastric carcinoma. Long-term prognosis including survival and mortality rates remains to be investigated. Above all, this study has shown that the higher dose lidocaine group experienced a significantly accelerated improvement in postoperative quality of recovery, while the differences in postoperative quality of recovery between the two other groups were not significant. Therefore, the combination of $1.5 \mathrm{mg} / \mathrm{kg}$ lidocaine bolus followed by continuous infusion at $2.0 \mathrm{mg} / \mathrm{kg} /$ hour is recommended for gastric cancer surgery to accelerate postoperative recovery.

\section{Conclusions}

Systemic lidocaine may enhance postoperative recovery, alleviate inflammation and immune suppression, and accelerate the return of bowel function for patients undergoing laparoscopic radical gastrectomy, effects which are worthy of clinical consideration.

\section{Data Sharing Statement}

The individual participant's data underlying the results reported in this article may be accessed with approval from the corresponding author 6 months after publication of this study. The study protocol, statistical analysis plan, and clinical study report will also be made available. 


\section{Acknowledgments}

The authors thank Dr. Long Wang for his support in inflammatory and immune factors testing. This work was supported by grants from the Qing Lan Project of Jiangsu Province; the Nature Science Foundation of Jiangsu Province (Code: BK20161175); the "Six One" Project of Jiangsu Province (Code: LGY2016039); Jiangsu Provincial Medical Youth Talent (QNRC2016796); Natural Science Research Project of Jiangsu Higher Education Institutions (Code: 17KJA3320006); and the Xuzhou Medical University Innovation Team. The funding was received by Dr. Su Liu. No commercial funding was received.

\section{Disclosure}

The authors report no conflicts of interest in this work.

\section{References}

1. Bray F, Ferlay J, Soerjomataram I, Siegel RL, Torre LA, Jemal A. Global cancer statistics 2018: GLOBOCAN estimates of incidence and mortality worldwide for 36 cancers in 185 countries. CA Cancer J Clin. 2018;68(6):394-424. doi:10.3322/caac.21492

2. Cervantes A, Roda D, Tarazona N, Rosello S, Perez-Fidalgo JA. Current questions for the treatment of advanced gastric cancer Cancer Treat Rev. 2013;39(1):60-67. doi:10.1016/j.ctrv.2012.09.007

3. Brenkman HJ, Haverkamp L, Ruurda JP, van Hillegersberg R. Worldwide practice in gastric cancer surgery. World $J$ Gastroenterol. 2016;22(15):4041-4048. doi:10.3748/wjg.v22. i15.4041

4. Arthur J, Hui D. Safe opioid use: management of opioid-related adverse effects and aberrant behaviors. Hematol Oncol Clin North Am. 2018;32(3):387-403. doi:10.1016/j.hoc.2018.01.003

5. Chen Z, Zhang P, Xu Y, et al. Surgical stress and cancer progression: the twisted tango. Mol Cancer. 2019;18(1):132. doi:10.1186/s12943019-1058-3

6. Hirai T, Matsumoto H, Yamashita K, et al. Surgical oncotaxis-excessive surgical stress and postoperative complications contribute to enhancing tumor metastasis, resulting in a poor prognosis for cancer patients. Ann Thorac Cardiovasc Surg. 2005;11(1):4-6.

7. Behrenbruch C, Shembrey C, Paquet-Fifield S, et al. Surgical stress response and promotion of metastasis in colorectal cancer: a complex and heterogeneous process. Clin Exp Metastasis. 2018;35 (4):333-345. doi:10.1007/s10585-018-9873-2

8. Beaussier M, Delbos A, Maurice-Szamburski A, Ecoffey C, Mercadal L. Perioperative use of intravenous lidocaine. Drugs. 2018;78(12):1229-1246. doi:10.1007/s40265-018-0955-x

9. de Oliveira CMB, Coelho LMG, Valadão JA, et al. Assessment of the effect of perioperative venous lidocaine on the intensity of pain and IL-6 concentration after laparoscopic gastroplasty. Obes Surg. 2020;30(10):3912-3918. doi:10.1007/s11695-020-04748-1

10. Ho MLJ, Kerr SJ, Stevens J. Intravenous lidocaine infusions for 48 hours in open colorectal surgery: a prospective, randomized, double-blinded, placebo-controlled trial. Korean $J$ Anesthesiol. 2018;71(1):57-65. doi:10.4097/kjae.2018.71.1.57

11. Yardeni IZ, Beilin B, Mayburd E, Levinson Y, Bessler H. The effect of perioperative intravenous lidocaine on postoperative pain and immune function. Anesth Analg. 2009;109(5):1464-1469. doi:10.1213/ANE.0b013e3181bab1bd
12. Sridhar P, Sistla SC, Ali SM, Karthikeyan VS, Badhe AS, Ananthanarayanan PH. Effect of intravenous lignocaine on perioperative stress response and post-surgical ileus in elective open abdominal surgeries: a double-blind randomized controlled trial. $A N Z$ J Surg. 2015;85(6):425-429. doi:10.1111/ans.12783

13. Song X, Sun Y, Zhang X, Li T, Yang B. Effect of perioperative intravenous lidocaine infusion on postoperative recovery following laparoscopic cholecystectomy-a randomized controlled trial. Int J Surg. 2017;45:8-13. doi:10.1016/j.ijsu.2017.07.042

14. Struys MM, Vanpeteghem C, Huiku M, et al. Changes in a surgical stress index in response to standardized pain stimuli during propofol-remifentanil infusion. Br J Anaesth. 2007;99(3):359-367. doi:10.1093/bja/aem173

15. Huiku M, Uutela K, van Gils M, et al. Assessment of surgical stress during general anaesthesia. Br $J$ Anaesth. 2007;98(4):447-455. doi:10.1093/bja/aem004

16. De Oliveira GS, Fitzgerald P, Streicher LF, et al. Systemic lidocaine to improve postoperative quality of recovery after ambulatory laparoscopic surgery. Anesth Analg. 2012;115(2):262-267. doi:10.1213/ ANE.0b013e318257a380

17. Myles PS. Measuring quality of recovery in perioperative clinical trials. Curr Opin Anaesthesiol. 2018;31(4):396-401. doi:10.1097/ ACO.0000000000000612

18. Gornall BF, Myles PS, Smith CL, et al. Measurement of quality of recovery using the QoR-40: a quantitative systematic review. $\mathrm{Br}$ $J$ Anaesth. 2013;111(2):161-169. doi:10.1093/bja/aet014

19. Herrera FJ, Wong J, Chung F. A systematic review of postoperative recovery outcomes measurements after ambulatory surgery. Anesth Analg. 2007;105(1):63-66. doi:10.1213/01.ane.0000265534.731 69.95

20. De Oliveira GS Jr, Duncan K, Fitzgerald P, Nader A, Gould RW, McCarthy RJ. Systemic lidocaine to improve quality of recovery after laparoscopic bariatric surgery: a randomized double-blinded placebo-controlled trial. Obes Surg. 2014;24(2):212-218. doi:10.1007/s11695-013-1077-x

21. Kim MH, Kim MS, Lee JH, Kim ST, Lee JR. Intravenously administered lidocaine and magnesium during thyroid surgery in female patients for better quality of recovery after anesthesia. Anesth Analg. 2018;127(3):635-641. doi:10.1213/ANE.0000000000002797

22. Cruickshank AM, Fraser WD, Burns HJ, Van Damme J, Shenkin A. Response of serum interleukin-6 in patients undergoing elective surgery of varying severity. Clin Sci (Lond). 1990;79:161-165. doi:10.1042/cs0790161

23. Kvarnstrom AL, Sarbinowski RT, Bengtson JP, Jacobsson LM, Bengtsson AL. Complement activation and interleukin response in major abdominal surgery. Scand J Immunol. 2012;75(5):510-516. doi:10.1111/j.1365-3083.2012.02672.x

24. Szczepanik AM, Scislo L, Scully T, et al. IL-6 serum levels predict postoperative morbidity in gastric cancer patients. Gastric Cancer. 2011;14(3):266-273. doi:10.1007/s10120-011-0039-z

25. Ortiz MP, Godoy MC, Schlosser RS, et al. Effect of endovenous lidocaine on analgesia and serum cytokines: double-blinded and randomized trial. J Clin Anesth. 2016;35:70-77. doi:10.1016/j. jclinane.2016.07.021

26. Herroeder S, Pecher S, Schnherr ME, et al. Systemic lidocaine shortens length of hospital stay after colorectal surgery: a double-blinded, randomized, placebo-controlled trial. Ann Surg. 2007;246 (2):192-200. doi:10.1097/SLA.0b013e31805dac11

27. Oliveira CM, Sakata RK, Slullitel A, et al. Effect of intraoperative intravenous lidocaine on pain and plasma interleukin-6 in patients undergoing hysterectomy. Rev Bras Anestesiol. 2015;65(2):92-98. doi:10.1016/j.bjan.2013.07.017

28. Lin E, Calvano SE, Lowry SF. Inflammatory cytokines and cell response in surgery. Surgery. 2000;127(2):117-126. doi:10.1067/ msy.2000.101584 
29. Ni Choileain N. Cell response to surgery. Arch Surg. 2006;141 (11):1132-1140. doi:10.1001/archsurg.141.11.1132

30. Larsen SK. Cellular immune responses towards regulatory cells. Dan Med J. 2016;63(1):B5188.

31. Brentville VA, Metheringham RL, Gunn B, et al. Citrullinated vimentin presented on MHC-II in tumor cells Is a target for CD4+ Tcell-mediated antitumor immunity. Cancer Res. 2016;76 (3):548-560. doi:10.1158/0008-5472.CAN-15-1085

32. Chen LJ, Zheng X, Shen YP, et al. Higher numbers of T-bet $(+)$ intratumoral lymphoid cells correlate with better survival in gastric cancer. Cancer Immunol Immunother. 2013;62(3):553-561. doi:10.1007/s00262-012-1358-6

33. Jackute J, Zemaitis M, Pranys D, et al. The prognostic influence of tumor infiltrating Foxp3(+) CD4(+), CD4(+) and CD8(+) T cells in resected non-small cell lung cancer. J Inflamm (Lond). 2015;12(1):63. doi:10.1186/s12950-015-0108-x

34. Chen M, Mohtize M, Matteï MF, et al. Reduced levels of both circulating CD4+ CD25+ CD127(low/neg) and CD4+ CD8(neg) invariant natural killer regulatory $\mathrm{T}$ cells in stable heart transplant recipients. Clin Exp Immunol. 2011;163(1):104-112. doi:10.1111/ j.1365-2249.2010.04281.x

35. Dewinter G, Moens P, Fieuws S, et al. Systemic lidocaine fails to improve postoperative morphine consumption, postoperative recovery and quality of life in patients undergoing posterior spinal arthrodesis. A double-blind, randomized, placebo-controlled trial. $\mathrm{Br}$ J Anaesth. 2017;118(4):576-585. doi:10.1093/bja/aex038

36. Tappenbeck K, Hoppe S, Reichert C, Feige K, Huber K. In vitro effects of lidocaine on contractility of circular and longitudinal equine intestinal smooth muscle. Vet J. 2013;198(1):170-175. doi:10.1016/j.tvj1.2013.07.027
37. Cook VL, Jones Shults J, McDowell M, Campbell NB, Davis JL, Blikslager AT. Attenuation of ischaemic injury in the equine jejunum by administration of systemic lidocaine. Equine Vet J. 2008;40 (4):353-357. doi:10.2746/042516408X293574

38. Lang A, Ben Horin S, Picard O, Fudim E, Amariglio N, Chowers Y. Lidocaine inhibits epithelial chemokine secretion via inhibition of nuclear factor kappa B activation. Immunobiology. 2010;215 (4):304-313. doi:10.1016/j.imbio.2009.05.006

39. de Boer HD, Detriche O, Forget P. Opioid-related side effects: postoperative ileus, urinary retention, nausea and vomiting, and shivering. A review of the literature. Best Pract Res Clin Anaesthesiol. 2017;31 (4):499-504. doi:10.1016/j.bpa.2017.07.002

40. Carabalona JF, Delwarde B, Duclos A, et al. Serum concentrations of lidocaine during bariatric surgery. Anesth Analg. 2020;130(1):e5-e8. doi:10.1213/ANE.0000000000003905

41. Weibel S, Jelting Y, Pace NL, et al. Continuous intravenous perioperative lidocaine infusion for postoperative pain and recovery in adults. Cochrane Database Syst Rev. 2018;6(6):CD009642. doi:10.1002/14651858.CD009642.pub3

42. Ye L, Zhang Y, Chen YJ, Liu Q. Anti-tumor effects of lidocaine on human gastric cancer cells in vitro. Bratisl Lek Listy. 2019;120 (3):212-217. doi:10.4149/BLL_2019_036

43. Johnson MZ, Crowley PD, Foley AG, et al. Effect of perioperative lidocaine on metastasis after sevoflurane or ketamine-xylazine anaesthesia for breast tumour resection in a murine model. Br J Anaesth. 2018;121(1):76-85. doi:10.1016/j.bja.2017.12.043

\section{Publish your work in this journal}

Drug Design, Development and Therapy is an international, peerreviewed open-access journal that spans the spectrum of drug design and development through to clinical applications. Clinical outcomes, patient safety, and programs for the development and effective, safe, and sustained use of medicines are a feature of the journal, which has also been accepted for indexing on PubMed Central. The manuscript management system is completely online and includes a very quick and fair peer-review system, which is all easy to use. Visit http://www. dovepress.com/testimonials.php to read real quotes from published authors. 